\title{
STUDIES OF THE MECHANISM OF ACTION OF COBAMIDE COENZYMES
}

\author{
R. H. Abeles and H. A. Lee, Jr. \\ University of Michigan Medical School, Ann Arbor, Mich.
}

Aerobacter aerogenes converts propanediol to propionaldehyde, and ethylene glycol to acetaldehyde. ${ }^{1}$ Dioldehydrase, the enzyme that catalyzes this reaction, has been purified 200-fold and a requirement for any one of three cobamide coenzymes and for a monovalent metal ion has been established. ${ }^{2}$ The present work seeks to extend the limited information $^{3}$ now available on the mechanism of action of cobamide coenzymes.

We have previously reported the following properties of the dioldehydrase system: $:^{4, \mathbf{5}}$

(1) The dioldehydrase reaction involves the replacement of a hydroxyl group at C-2 of the diol by a hydrogen atom. It was demonstrated that the hydrogen did not arise from the solvent but originated from C-1 of the diol.

(2) When the substrate was propanediol-1- $D_{2}$, a large isotope effect was observed; the deuterated substrate reacting at one-tenth the rate of the nonisotopic compound.

(3) Formation of a fully active enzyme-coenzyme complex appears to be a relatively slow process, since a lag period is observed prior to attainment of maximal velocity when the enzyme, coenzyme and substrate are mixed simultaneously. Incubation of the enzyme and coenzyme prior to substrate addition eliminates the lag period.

After complex formation certain properties of the apoenzyme and the coenzyme are markedly altered: no inactivation by $p$-hydroxy-mercuribenzoate occurs and the coenzyme is no longer light sensitive.

(4) In the absence of substrate the enzyme-coenzyme complex becomes inactive; both coenzyme and enzyme activity are lost. This inactivation is accompanied by a spectral change which results in a spectrum very similar to hydroxo-cobalamin.

These results suggested that the enzyme is capable of modifying the coenzyme, possibly by breaking the carbon-cobalt bond, and this process may reflect an important aspect of the actual catalytic process. Since during the catalytic process the coenzyme activity is not lost, a reversible modification needs to be postulated. Based upon these considerations, we wish to propose the following tentative scheme for the reaction:

(1) $\mathrm{E}+\mathrm{DBCC} \rightarrow \mathrm{E} \cdot \mathrm{DBCC}$

(2) $\mathrm{E} \cdot \mathrm{DBCC}+\mathrm{S} \rightleftarrows \mathrm{E} \cdot \mathrm{DBCC} \cdot \mathrm{S}$

(3) $\mathrm{E} \cdot \mathrm{DBCC} \cdot \mathrm{S} \rightleftarrows \mathrm{E} \cdot \mathrm{DBCC}^{*} \cdot \mathrm{I}$

(4) $\mathrm{E} \cdot \mathrm{DBCC}^{*} \cdot \mathrm{I} \rightarrow \mathrm{E} \cdot \mathrm{DBCC}+\mathrm{P}$.

In this scheme E.DBCC represents the enzyme-coenzyme complex, $\mathrm{E} \cdot \mathrm{DBCC}$ a complex of the enzyme and a modified form of the coenzyme, and I an intermediate derived from the substrate $S$, and a precursor of the product $P$. 
Recently we have obtained evidence that a reversible modification of the coenzyme occurs during the conversion of propanediol to propionaldehyde. When the substrate is added to the enzyme and DBCC a spectral shift is observed (FIGURE 1). The original spectrum is again observed

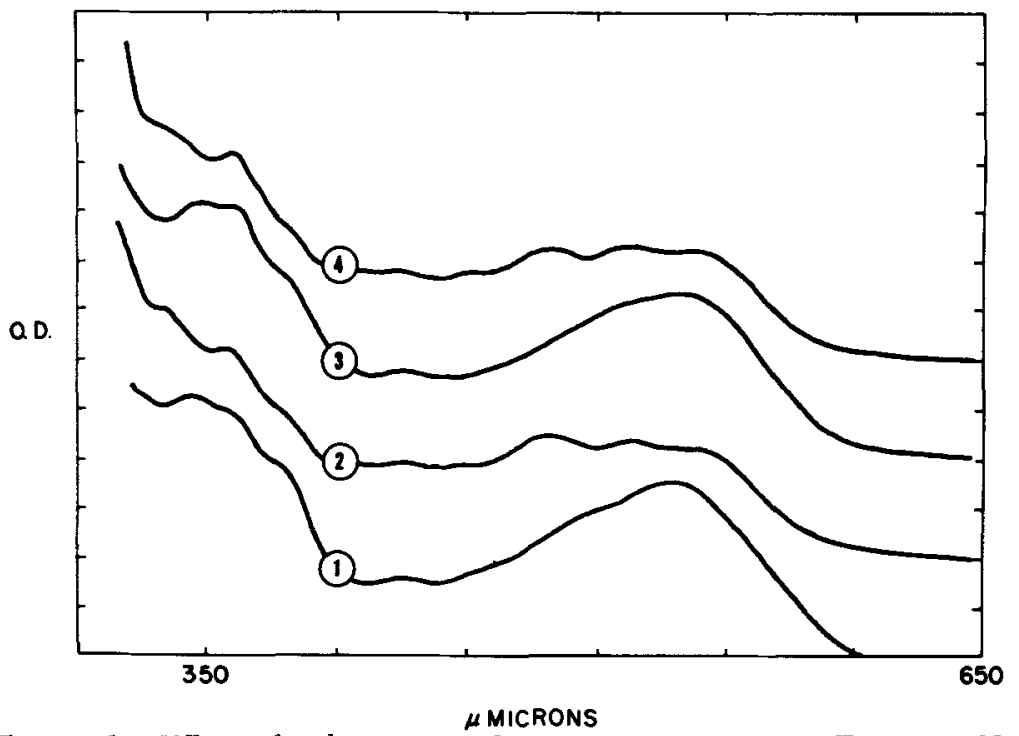

Figure 1. Effect of substrate on the coenzyme spectrum. Enzyme 108 units, DBCC $20 \mu$ moles, $7 \mu$ moles $\mathrm{K}_{2} \mathrm{HPO}_{4}$, vol. $0.8 \mathrm{ml}$., $23^{\circ} \mathrm{C}$. The following additions were made; Spectrum 1: none; Spectrum 2: $80 \mu$ moles ethylene glycol; Spectrum 3: None (all substrate utilized at this point); Spectrum 4: $500 \mu$ moles ethylene glycol.

after the substrate is utilized. Further addition of substrate again produces a spectral change. We attribute these spectral changes to a reversible modification of the coenzyme during the course of the reaction. The specie which give rise to the new spectrum would correspond to $\mathrm{DBCC}^{*}$ of the above scheme.

A number of compounds were then screened with the hope of finding a compound which could take part in reactions 1-3 to a significant extent but where reaction 4 occurs slowly or not at all. This would enable us to investigate the nature of the intermediate (I) and DBCC* The initial screening of the compound was carried out by measuring the inhibition of the conversion of propanediol to propionaldehyde. Glycolaldehyde was the most promising of the compounds tested. The inhibition obtained with this compound is shown in FIGURE 2 . The addition of glycolaldehyde to the reaction brings about total inhibition. The time required for total inhibition is dependent upon the amount of substrate present. The protection by substrate suggests common sites of interaction for the two compounds.

The inhibition obtained with glycolaldehyde cannot be reversed by

${ }^{*}$ DBCC = dimethyl benzimadazolyl-cobamide coenzyme. 
further addition of substrate, or coenzyme. Only the addition of enzyme leads to restoration of activity. These results indicate that glycolaldehyde leads to the inactivation of the enzyme. Furthermore, this inhibition is

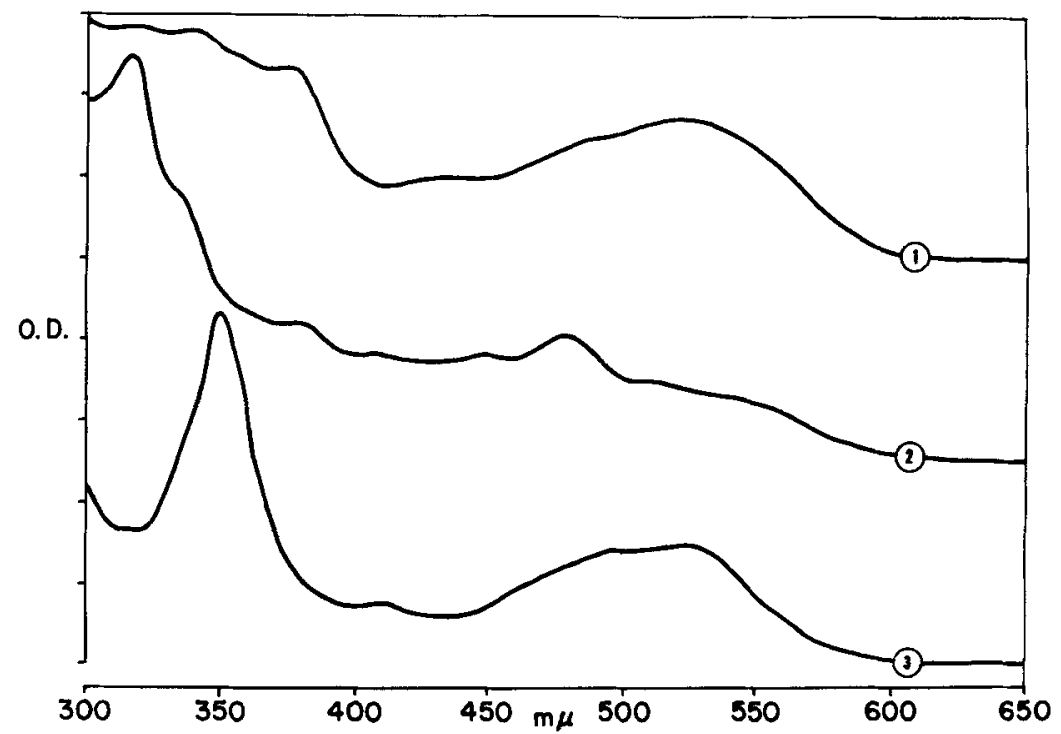

FIGURE 2. Effect of glycolaldehyde on the coenzyme spectrum. Enzyme 164 units, DBCC $30 \mu$ moles, $7 \mu$ moles $\mathrm{K}_{2} \mathrm{HPO}_{4}$, vol. $0.8 \mathrm{ml}$, $23^{\circ} \mathrm{C}$. The following additions were made; Spectrum 1: none; Spectrum 2: $40 \mu$ moles glycolaldehyde; Spectrum 3: $\mathrm{HCl}$ final conc. $0.02 \mathrm{~N}$.

coenzyme-dependent since incubation of the enzyme with glycolaldehyde in the absence of coenzymes does not lead to inactivation.

In the experiments described so far the coenzyme concentration far exceeded that of the enzyme. When enzyme and coenzyme concentrations are more nearly equivalent, coenzyme inactivation is observed as well as enzyme inactivation, as shown in TABLE 1.

TABLE 1

Inactivation of Enzyme and DBCC by Glycolaldehyde

\begin{tabular}{l|c|c}
\hline \hline \multicolumn{1}{c|}{ Reaction mixture } & $\begin{array}{c}\text { Enzyme inactivated } \\
\text { units }\end{array}$ & $\begin{array}{c}\text { DBCC inactivated } \\
\text { m } \mu \text { moles }\end{array}$ \\
\hline Enzyme, DBCC & 5 & 0.9 \\
Enzyme, DBCC, Glycolaldehyde & 39.5 & 5.0 \\
\hline
\end{tabular}

Enzyme 59 units, DBCC 10 mumoles, glycolaldehyde $10 \mathrm{~m} \mu$ moles, $\mathrm{K}_{\mathbf{2}} \mathrm{HPO}_{4} 5$ $\mu$ moles, total volume: $0.7 \mathrm{ml} ., 5 \mathrm{~min} ., 30^{\circ} \mathrm{C}$.

In view of the requirement of a mono-valent metal ion for the conversion of propanediol to propionaldehyde, the $\mathrm{K}^{+}$dependence of the gly- 
TABLE 2

$\mathrm{K}^{+}$Requirement for Glycolaldehyde Inactivation

\begin{tabular}{l|c}
\hline \multicolumn{1}{c|}{ Reaction Mixture } & Relative Activity \\
\hline Enzyme $+\mathrm{K}^{+}$ & 100 \\
Enzyme & 80 \\
Enzyme $+\mathrm{K}^{+}+\mathrm{GA}$ & 100 \\
Enzyme $+\mathrm{K}^{+}+\mathrm{DMBC}$ & 58 \\
Enzyme $+\mathrm{K}^{+}+\mathrm{DMBC}+\mathrm{GA}$ & 22 \\
Enzyme + DMBC + GA & 76 \\
Enzyme + DMBC & 73 \\
\hline \hline
\end{tabular}

Enzyme .065 units, KCL $80 \mu$ moles, DBCC 0.3 m $\mu$ moles, glycolaldehyde (GA) $0.1 \mu$ moles, volume $1.0 \mathrm{ml}$., $15 \mathrm{~min} ., 37^{\circ} \mathrm{C}$.

colaldehyde inactivation was tested. The results are given in TABLE 2. Incubation of the enzyme, DBCC, and glycolaldehyde in the absence of potassium produces no more inactivation than when glycolaldehyde is omitted. Increased inactivation results from the addition of glycolaldehyde in the presence of potassium. Thus, the inactivation by glycolaldehyde requires potassium ion, as does the reaction involving the substrate.

The effect of glycolaldehyde upon the spectrum of the enzyme-coenzyme complex was examined. The results are shown in FIGURE 3 . The observed spectrum is qualitatively similar to that obtained in the presence

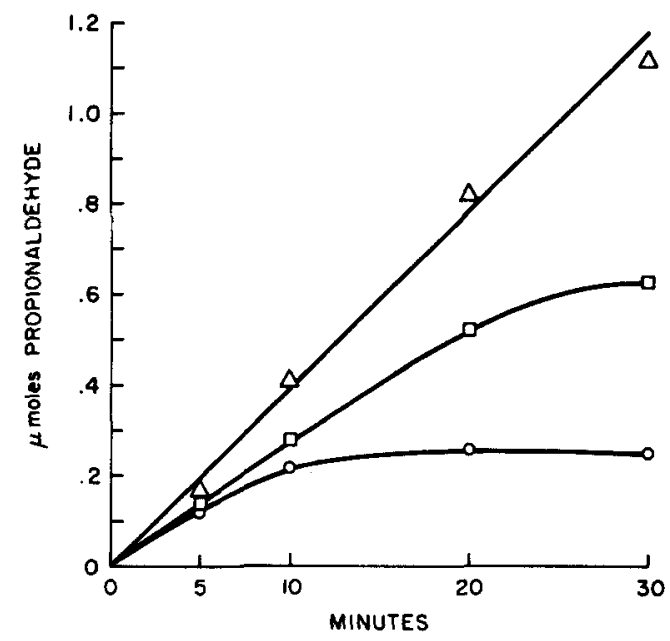

Figure 3. Effect of glycolaldehyde on the rate of propionaldehyde formation. Enzyme 0.06 units/ml., $\mathrm{K}_{2} \mathrm{HPO}_{4} 0.040 \mathrm{M}, \mathrm{pH} 8.0, \mathrm{DBCC} 1.25 \mu M . \triangle$ : 1,2-propanediol $0.010 M, \square:$ 1,2-propanediol $0.040 \mathrm{M}$, glycolaldehyde $2 \times 10^{-4} \mathrm{M}, \mathrm{O}: 1,2$-propanediol $0.010 \mathrm{M}$, glycolaldehyde $2 \times 10^{-4} \mathrm{M}, 30^{\circ} \mathrm{C}$. 
of the substrate, except that a larger fraction of the coenzyme seems to have been converted to the modified form (DBCC). This spectral change is irreversible in contrast to the reversible change obtained when propanediol is present in place of glycolaldehyde.

The effect of low $p H$ on the spectra of the various mixtures provides further evidence for the modification of the coenzyme by the enzyme in the presence of glycolaldehyde. When acid is added to DBCC per se, a typical spectral shift is observed. ${ }^{6}$ A similar shift is obtained when the coenzyme is mixed with enzyme and immediately treated with acid. However, when the coenzyme, enzyme, glycolaldehyde mixture is acidified, a new absorption peak is obtained at $350 \mathrm{~m} \mu$, as indicated in FIGURE 3 . This spectrum closely resembles that of hydroxo-cobalamin.

In order to determine the nature of the compounds formed by inactivation of the coenzyme, cobalt ${ }^{60}-\mathrm{DBCC}$ was used as follows. The labeled coenzyme was incubated with enzyme, as described in TABLE 3 , in the

TABLE 3

INACTrVATtON OF $\mathrm{Co}^{60} \mathrm{DBCC}$

\begin{tabular}{l|c|c}
\hline \hline \multirow{2}{*}{ Reaction mixture } & \multicolumn{2}{|c}{ Recovery in supernatant fluid } \\
\cline { 2 - 3 } & $\begin{array}{c}\mathrm{Co}^{60} \\
(\mathrm{cpm})\end{array}$ & $\begin{array}{r}\text { DBCC } \\
(\%)\end{array}$ \\
\hline Enzyme, DBCC (3 min.) & 3336 & 100 \\
Enzyme, DBCC (30 min.) & 2916 & 23 \\
Enzyme, DBCC, GA (3 min.) & 2856 & 11 \\
DBCC & 3366 & 100 \\
\hline \hline
\end{tabular}

Enzyme 12.5 units, DBCC $5 \mu$ moles, glycolaldehyde (GA) $1 \mu$ mole, vol. $0.7 \mathrm{ml}$, $30^{\circ} \mathrm{C}$. Reaction times as indicated. Trichloracetic acid was added to a final concentration of $0.2 \mathrm{M}$, and the supernatant fluid analyzed.

presence and absence of glycolaldehyde. After precipitation of the protein with TCA, the supernatant fluids were analyzed for $\mathrm{Co}^{60}$ and for coenzyme activity. A minimum of 85 per cent of the $\mathrm{Co}^{60}$ was recovered in the supernatant fluid in all experiments. However, after prolonged incubation of the enzyme and coenzyme or after short incubation of coenzyme and enzyme in the presence of glycolaldehyde, most of the coenzyme activity was destroyed. These data suggest the formation of an inactive compound containing $\mathrm{Co}^{60}$ derived from $\mathrm{DBCC}$. This product was tentatively characterized as hydroxo-cobalamin by electrophoresis and thin layer chromatography. Electrophoresis was carried out in $0.5 \mathrm{M}$ acetic acid and $0.5 \mathrm{M} \mathrm{NH}_{4} \mathrm{OH}$. The chromatographic system was isopropanol:1 per cent $\mathrm{NH}_{4} \mathrm{OH}(2: 1)$ with silicic acid as supporting medium. In every case the radioactivity in the reaction in which inactivation had occurred, chromatographed with an $R_{f}$ identical with hydroxo-cobalamin. These results show that when DBCC is modified by dioldehydrase, in the absence or presence of glycolaldehyde, hydroxo-cobalamin (or a 
compound converted to hydroxo-cobalamin by acid) is formed. These findings are consistent with the hypothesis that the enzyme is capable of breaking or modifying the carbon-cobalt bond.

We also attempted to establish the fate of glycolaldehyde during the course of the coenzyme inactivation. For this purpose, glycolaldehyde2 - $\mathrm{C}^{14}$ was synthesized and incubated with enzyme and coenzyme. At the end of the incubation the enzyme was precipitated by the addition of salt. Radioactivity was found tightly bound to the protein as well as in the supernatant fluid. Not all of the activity in the supernatant fluid was glycolaldehyde. The material bound to the protein could not be removed by extensive washing.

As indicated in TABLE 4, the loss of coenzyme activity is approximately equal to the amount of glycolaldehyde that reacts in this system.

TABLE 4

Storchiometry of Coenzyme Inactivation by Glycolaloehyde-2-C ${ }^{14}$

\begin{tabular}{l|c|c}
\hline & Exp. 1 & Exp. 2 \\
\hline Enzyme inactivated & 290 units & 195 units \\
DBCC inactivated & 36 m $\mu$ moles & 27 m $\mu$ moles \\
Glycolaldehyde Reacted & $44 \mathrm{~m} \mu$ moles & 28 m $\mu$ moles \\
\hline
\end{tabular}

Incubation time, $20 \mathrm{~min}$., temp. $30^{\circ} \mathrm{C}$.

Exp. 1, enzyme 325 units, DBCC 50 m $\mu$ moles, glycolaldehyde-2- $\mathrm{C}^{14} 60 \mathrm{~m} \mu$ moles.

Exp. 2, enzyme 210 units, DBCC 38 m $\mu$ moles, glycolaldehyde-2-C ${ }^{14} 40$ mumoles.

The reactions were stopped by the addition of lithium formate to a final concentration $0.1 M$, which resulted in the precipitation of the protein. After addition of carrier glycolaldehyde to the supernatant fluid, the glycolaldehyde was precipitated as its dimedon derivative. The remaining $\mathrm{C}^{14}$ in the supernatant fluid and that bound to the protein represent reacted glycolaldehyde. Approximately 50 per cent of the glycolaldehyde that reacted was protein bound.

We subsequently found that the activity associated with the precipitated protein could be solubilized by the addition of TCA. Therefore in subsequent experiments the reaction was stopped by the addition of TCA which resulted in the recovery of all of the added activity in the soluble form. When such reaction mixtures were examined it was found that a fraction (50-90 per cent) of the activity could be isolated as dimedon adduct of glycolaldehyde after the addition of glycolaldehyde carrier, and from $80-100$ per cent of the remaining activity could be isolated as glyoxal-semicarbazone after the addition of glyoxal carrier. A portion of the reaction mixture was also oxidized with $\mathrm{NaIO}_{4}$ to convert the $\alpha$-carbon of the glycolaldehye to formaldehyde, which was then isolated as formaldomethone. The results of such an experiment are shown in TABLF 5. In the control experiment where the coenzyme was omitted, the specific activity of the formaldomethone is, as expected, identical with that of the glycolaldehyde dimedon adduct. In the complete reaction mixture the specific activity of the formaldomethone is lower than that of the glycolaldehyde derivative. These results indicate isomerization (i.e., in- 
TABLE 5

Degradation of Glycolaldemyde

\begin{tabular}{l|cr}
\hline \multirow{2}{*}{ Compound isolated } & \multicolumn{2}{|c}{ Specific activity $(\mathrm{cpm} / \mu$ mole) } \\
\cline { 2 - 3 } \multicolumn{1}{c|}{ Glycolaldehyde dimedon } & Reaction & Control \\
$\mathrm{CH}_{2} \mathrm{O}$-dimedon & 74.7 & 162 \\
\hline
\end{tabular}

Enzyme 97 units, DBCC $15.6 \mathrm{~m} \mu$ moles, glycolaldehyde 15 mumoles, vol. $5 \mathrm{ml}$., $30^{\circ} \mathrm{C}$., $10 \mathrm{~min}$. DBCC omitted from control.

terconversion of C-1 and C-2) of glycolaldehyde. In the presence of enzyme and coenzyme, glycolaldehyde is partially isomerized and partially converted to a different substance, probably glyoxal. The relative extent to which these two reactions occur varies from experiment to experiment under apparently identical reaction conditions. The reason for this inconsistency is not clear at this time.

Isomerization of glycolaldehyde could arise either through a transfer of a hydride from the $\alpha$-carbon to the carbonyl-carbon or through the formation of a symmetrical intermediate such as the ene-diol of glycolaldehyde. The glyoxal could possibly arise through air oxidation of this ene-diol and may be a secondary product, rather than the direct result of enzyme action.

To summarize these results: (1) Incubation of enzyme, coenzyme, and substrate gives reversible spectral shifts. Similar but irreversible spectral shifts were noted when glycolaldehyde was substituted for propanediol as substrate. (2) Reaction of the enzyme with glycolaldehyde resembled the reaction with propanediol in its requirement for potassium ion. (3) Kinetic data suggest that glycolaldehyde and propanediol compete for the same binding site on the enzyme surface. (4) Inactivation of the coenzyme by enzyme, in the presence or absence of glycolaldehyde, followed by acidification, lead to the formation of a substance tentatively identified as hydroxo-cobalamin. (5) The inactivation process in the presence of glycolaldehyde results in the conversion of glycolaldehyde to glyoxal and to its isomerization.

Due to the inactivation of enzyme and coenzyme the reaction with glycolaldehyde does not involve a catalytic process, whereas in the conversion of propanediol to propionaldehyde the enzyme and coenzyme clearly serve a catalytic function. We have however, presented evidence that the two processes are in fact very similar. We would like to suggest the following tentative explanation for this apparent discrepancy. Both glycolaldehyde and propanediol can undergo reaction 2 and 3 of the reaction sequence proposed earlier in this paper, but in the presence of glycolaldehyde, reaction 4 does not occur, and the enzyme-DBCC complex is not regenerated. This prevents further reaction and results in enzyme inactivation. The irreversible conversion of DBCC to $\mathrm{DBCC}^{*}$ leads to loss of coenzyme activity. Therefore, the loss of enzyme and coenzyme activity can be explained by assuming that reaction 4 of the 
proposed reaction sequence does not occur when glycolaldehyde is the substrate.

The proposed reaction sequence requires that concomitant with the formation of DBCC an equivalent amount of glycolaldehyde should undergo some chemical reaction. We have shown this to be the case. The products formed from glycolaldehyde remain to be fully charactexized. It was pointed out previously that the results obtained so far are subject to a number of interpretations. When sufficient evidence is obtained so that the reaction which glycolaldehyde undergoes can be unequivocally explained, the chemistry of reaction 3 will be understood, and thus we believe, an essential aspect of the mechanism of action of the cobamide coenzyme.

At this time insufficient experimental evidence is available to discuss the mechanism by which the cobamide coenzyme could take part in the reactions described. However, the recently discovered chemistry ${ }^{3,6-10}$ of the cobamide coenzymes suggests some possibilities. Rupture of the carbon-cobalt bond analogous to that described for the acid hydrolysis of the coenzyme can produce an electrophylic cobalt, which could serve as an acid, and an anion, derived from the adenosine moiety, which could serve as a base in a catalytic process. Alternately, one could envision a rupture of the carbon-cobalt bond which results in a nucleophylic cobalt. Although no chemical analogy exists as yet for the breaking of the carbon-cobalt bond in this manner, the reactivity of such a compound, which has been amply illustrated ${ }^{10,11}$ makes this an attractive intermediate in the enzyme process. These suggestions concerning the mode of action of the coenzyme are clearly speculative and further experimental results are needed to support or refute these possibilities.

\section{Acknowledgment}

This work was supported by a grant from the National Institutes of Health. The authors wish to thank E. R. Squibb and Sons for a gift of DBCC and DBCC-Co ${ }^{60}$ and also D. Perlman for his very generous cooperation in providing necessary materials.

\section{References}

1. Abeles, R. H. \& H. A. Lee, Jr. 1961. J. Biol. Chem. 236: 2347.

2. Lee, H. A. JR. \& R. H. Abeles. J. Biol. Chem. In press.

3. Barker, H. A. 1961. Fed. Proc. 20: 956.

4. Brownstern, A. M. \& R. H. Abeles. 1961. J. Biol. Chem. 236: 1199.

5. Abeles, R. H. \& H. A. LeE, JR. 1962. Brookhaven Symposia in Biol. 15: 310.

6. Ladd, J. N., H. P. C. Hogencamp \& H. A. Barker. 1961. J. Biol. Chem. 236: 2114.

7. Hogencamp, H. P. C. 1963. This Annals.

8. Smith, E. L., L. Mervyn, A. W. Johnson \& N. Shaw. 1962. Nature. 194: 1175.

9. Bernhauer, K. \& O. Müller. 1961. Biochem. Z. 334: 199.

10. Müllef, O. \& G. Müller. 1961. Biochem. Z. 336: 299.

11. Smith, L. E., L. Menyyn, P. W. Mugcleton, A. W. Johnson \& N. Shaw. 1963. This Annals. 